\title{
Methodologies and Tools to Support Design and Development of New Products
}

\author{
Ana Dias ${ }^{1}$, António Abreu ${ }^{1}$ and João Matias ${ }^{2}$ \\ ${ }^{I}$ Mechanical Engineering Departamental Area, Superior Institute of Engineering of Lisbon, Lisbon, Portugal \\ ${ }^{2}$ Electromechanical Engineering Department, Beira Interior University, Covilhã, Portugal
}

Keywords: $\quad$ New Product Development, Graph, NPD Tools, Innovation, Suppliers, Quality, Project, Decision.

\begin{abstract}
Nowadays, companies, even the small ones, need to use more efficient working methods such as "transnational." The market may still be local or regional, but the competition is global. To be competitive, companies need to develop innovative products and introduce them to the market at an acceptable price, in proper time and with a higher quality level. According to some authors, the survival strategy of the companies is related to the development of methodologies that are able to design, develop and provide, through efficient processes, innovative products and high quality. In this context, this paper aims to classify and characterize the main methodologies and tools used in new products development. This aims are supported by the graphs theory that is briefly addressed.
\end{abstract}

\section{INTRODUCTION}

The increasing globalization of markets, especially in the last decade, caused profound changes in the structure, organization and manner of operation of businesses. The working methods and management of the past are less and less adapted to the turmoil of the modern world. In the current world scenario, at the macroeconomic level is possible to identify a set of variables that influence the competitiveness of companies, for example, the energy crisis associated with the continuous increase in oil prices and the emergence of new trading powers, such as China and India, have all created new threats to European Industry (De Feo and Bar-El, 2002).

In order to be competitive companies must develop capabilities that will enable them to respond quickly to market needs. Nowadays it's possible to identify variables that influence the development of production processes such as market pressures to: improving quality, reducing production time and costs, increased production flexibility and concentration on core competences (Finster, 2001).

On the other hand, the product life cycle is becoming shorter which strongly increases the rate at which the process of design and/or development of new products occur. The most frequently introduction of new products in the market with shorter intervals of time has been, in recent times, the survival strategy of some companies to win new customers and as a response to the diversity of options available (Christopher, 1992) and (Creveling, 2003).

Based on a survey and applying the graph theory this article contributes to identify and characterize the main methodologies and tools used in processes of new products development (NPD), and their interrelationships among them.

\section{TOOLS USED IN NPD}

Base on literature a number of tools/methodologies focused on different perspectives to support NPD processes have been proposed over time in various disciplines.

From literature review carried out, it was found that there is no consensus regarding the terminology of methodology and tool, that means these concepts are mistaken for each other (Sun and Zhao, 2010). Therefore, in this article, are considered as "methodological tools" those that are both methodologies and tools, and as "instrumental tools" those that are used as support of methodological.

In order to identify the most relevant tools used in NPD and their inter-relations, a survey on web of 
science (549 articles were selected, gathering the period between 2002 and 2013) was conducted. Taking into account the data collected, the tools were divided in groups, regarding de theme that matches with each tool under the NPD. Table 1 shows some examples of associated tools to NPD processes.

Table 1: Classification of NPD supporting tools.

\begin{tabular}{|c|c|c|}
\hline \multirow{2}{*}{ Discipline } & \multicolumn{2}{|c|}{ Tools/Methodologies } \\
\hline & Methodological & Instrumental \\
\hline \multirow{3}{*}{ Project } & $\begin{array}{c}\text { TRIZ (theory for } \\
\text { inventive problem } \\
\text { solving) }\end{array}$ & $\begin{array}{c}\text { ARIZ; Matrix of } \\
\text { contradictions; S- } \\
\text { Field model } \\
\end{array}$ \\
\hline & Creative design & $\begin{array}{l}\text { Analogy-based } \\
\text { design }\end{array}$ \\
\hline & Axiomatic Design & $\begin{array}{l}\text { Pugh analysis; } \\
\text { DOE; DFX }\end{array}$ \\
\hline Logistics & $\begin{array}{c}\text { Suppliers } \\
\text { Development } \\
\text { Involvment (SDI) }\end{array}$ & \\
\hline \multirow[t]{2}{*}{$\equiv \square 1 \equiv$} & $\begin{array}{l}\text { Quality Function } \\
\text { Development } \\
\text { (QFD) }\end{array}$ & $\begin{array}{c}\text { Kano model; House } \\
\text { of quality (HOQ); } \\
\text { Balanced Scorecard } \\
\text { (BSC); Ishikawa or } \\
\text { Fishbone analysis; } \\
\text { Design for Failure } \\
\text { Modes and Effects } \\
\text { Analysis } \\
\text { (DFMEA); Pareto } \\
\text { or ABC analysis }\end{array}$ \\
\hline & $\begin{array}{l}\text { Design for Six } \\
\text { Sigma (DFSS) }\end{array}$ & $\begin{array}{c}\text { DFSS cycles } \\
\text { (DMADV, DCCDI, } \\
\text { DCOV, DDOV, } \\
\text { DMADIC, } \\
\text { DMADOV, } \\
\text { DMEDI, ICOV, } \\
\text { IDOV, ID }{ }^{2} \mathrm{OV}, \\
\text { I }^{2} \text { DOV e PIDOV) }\end{array}$ \\
\hline \multirow{3}{*}{ Design Support } & Robust design & \\
\hline & Tolerance design & \\
\hline & Modular design & \\
\hline $\begin{array}{l}\text { Decision } \\
\text { Support }\end{array}$ & $\begin{array}{c}\text { Analytical } \\
\text { Hierarchy Process } \\
\text { (AHP) }\end{array}$ & $\begin{array}{c}\text { Case Based } \\
\text { Reasoning (CBR); } \\
\text { Data Envelopment } \\
\text { Analysis (DEA); } \\
\text { Delphi panel } \\
\end{array}$ \\
\hline
\end{tabular}

\section{SURVEY FINDINGS}

\subsection{Brief Decription of Methodological Tools to Support NPD}

Among the tools to support innovation and creativity, TRIZ that means in English: "Theory for Inventive Problem Solving", and is a specific support for innovation development project, product or process engineering or technology. More surprisingly, the reference of the concept TRIZfractal that means self-similarity in transformations based on TRIZ tools to address knowledge management TRIZ (Pin et al., 2011) uses the matrix of contradictions and innovative principles in order to solve problems (Berdanosov and Redkolis, 2011).

Another tool of this group is known as "Creative Design". Creativity is necessary to generate alternative solutions, requiring the involvement of the designer or the creative team responsible for the design. This process has not only creative inspiration and imagination with these people, but also with methods and tools that allow the manifestation of creativity. There is research indicating that creativity to find solutions to product design, comes often in direct analogy with nature, and hence the concept of "Bionic" which consists in analyzing the functioning of natural systems or processes, reproducing after their early solution (Detanico, 2010). From this analogy often arise new outstanding contributions in the process of NPD. These adaptations allow the creation of forms, functions, or even similar conduct. A creative design analogy is an important reasoning process that allows the generation of new artifacts, using ideas from the fields of technical and/or scientific sometimes distant. Such is the case with analogues derived from nature. Here therefore a good creative genesis for the project: the analogy: it is designated as "the design approach based on analogy" (Gomes et al., 2006).

Yet another tool of this group is known as "Axiomatic Design" that is a tool for creating solutions synthesized with the aim of developing products, processes or systems that satisfy perceived needs through the mapping of customer desires in "Functional Requirements" (FRs) turning them into "Design Parameters" (DPs) (Yang and El-Haik, 2009). Functional requirements represent the goals of the project that means the aims to be achieved ( $\mathrm{Li}$ et al., 2011). There are some vulnerabilities concerning the axiomatic design: violation of their two axioms, by coupling systems; or by the complexity. That is why it is understood that the DFSS can help overcome these problems. Regardless of the vulnerabilities identified, the axiomatic design is a methodological tool designed to analyze in a systematic way, the transformation of customer needs, FRs into DPs and relating them (Yang and El-Haik, 2009).

One tool from logistics group corresponds to the involvement of suppliers in NPD. Many authors have demonstrated empirically that a NPD draft 
participating vendors, induce many benefits particularly in terms of reducing lead-times, reduced project costs, including product and quality improvement project and product (Wynstra, et al., 2012). That is, the Suppliers Development Involvement (SDI) has a decisive effect on the performance of a NPD project. There were detected three distinct factors that make up the apparent involvement of suppliers (Jayaram, 2008): information sharing and communication, involvement in the project itself; quality compliance and development of related infrastructure. That means supplier involvement in NPD clearly comprises a multidimensional perspective.

Quality Function Deployment (QFD), following the philosophy of "Total Quality Management (TQM)", and has been considered as a strategy that the entire organization is focused on continuous improvement (Li et al., 2012) and (Mendonça et al., 2007). This entrepreneurial attitude has necessarily to take into account at all times the will and needs of customers (Ghinato, 1998). Approach in the context of methodologies and tools based on the Quality function, integrates undoubtedly the strategy or methodology is portrayed primarily by its specific tools or others associated with the project, production or innovation (Ghinato, 1998). In support of this assertion, were correlated in a robust manner, greater speed in NPD with a more demanding of quality processes and related tools (Sun and Zhao, 2010). As instrumental tools of QFD, the best known are "House of Quality" (HOQ), Kano model, BSC/KPIs (Balanced Scorecard/Keys Performance Indicators), Failure Modes and effects Analysis/Design Failure Modes and Effects Analysis (FMEA/DFMEA), cause-effect or fishbone diagram (also known as the Ishikawa diagram) and Pareto or $\mathrm{ABC}$ analysis.

Design for Six Sigma (DFSS) is a methodological tool project developed under the Six Sigma (SS) philosophy in order to support continuous improvement in the stage of mass production and whose focus is the design and development of profitable products, processes and services, meeting the needs and expectations of customers (voice of customer) and other stakeholders (Jou, et al., 2010), including suppliers as already noted. This aim involves the use of an integrated set of tools, in order to provide and improve the quality level obtained before the start of production or harvesting. SS approach focuses on the production phase and/or operation and DFSS has its focus on the design and development phase. Thus, it is possible to substantially reduce the costs associated with the life cycle of the product, service or process, since the DFSS is a preventive approach (Yang and El-Haik, 2009), which aims to predict the occurrence of failures and prevent unfold in stages following. DFSS, whose methodology based (the first one came and that subsequently led variants, is the DMADV. SS philosophy was developed precisely to achieve this goal. DFSS as well as their tools instrumental also called cycles (Shahin, 2008): "Define, Measure, Analyze, Improve, Control" (DMAIC)/"Define, Measure, Analyze, Design, Verify" (DMADV) among others, can considered as an integrated whole in the universe's most comprehensive quality or DFSS methodology (Shahin, 2008).

A tool from the support design decision group is the "Robust Design". Terminological factors are referred to as "noise", such as temperature, humidity, dust, deterioration, and so on. Which are the cause of these deviations which result is loss of product quality. Such damage can be evaluated using a function "loss" which was initially proposed by Lee and Tang (2000). Such a proposal is to determine the loss function of the product, to optimize through statistical techniques. Such analyzes allow us to identify the optimal parameters of draft which minimizes or eliminates the harmful influence of such factors "noise", product performance or NPD. Thus, instead of isolating the product to develop the noise factor, which in addition to any hard execution, can become expensive undoubtedly the production process, the robust engineering presents itself instead as a valid proposal to implement projects that eliminate these same factors noises in the product's intention. Taguchi method consists in obtaining products sufficiently robust in order to achieve high quality with respect to any fluctuations that influence the environment of the NPD and even those that may occur during the production process (Kang et al., 2007).

Another tool from the previous noticed group is the "Tolerance Design". DFSS usually uses to drive defects per million opportunities (DPMO) (Santos, 2009). This measurement is the average number of defects per unit normalized, if one million, seen during a production sample mean, divided by the number of opportunities for the existence of a product defect, a defect is considered as noncompliance with requirements. These requirements are defined in the specification or tolerance of products or processes, still in the design phase of the NPD, and can determine one or more forms of production of each of the component parts, rather than the use of other processes (Singh, et al., 2005). 
It is therefore a tool methodological tools that can use instruments towards the optimization of tolerances even before the actual geometric dimensioning (Zhang et al., 2010). A robust engineering is not compatible with large projects with dimensioning of clearances that have tolerated maintenance costs outside the criteria of a six sigma production (Hagen and Park, 2013). This is therefore a design type intended mainly for the production and construction of machines, organs and parts where the gaps are tolerated function of the dynamic equilibrium and stability of the structure as a whole.

The last tool from the same group as the two last noticed is the "Modular Design", it corresponds to the outsourcing, both parts of the project, as production parts or components to a third logistics part (31p), whose integration is a crucial task both with respect to the phases of the project, such as when outsourcing regards the production process (Salvador and Villena, 2013). The modular design can be presented by the facet of knowledge sharing in NPD, and conclude that this strategy has positive impacts on their organizations and products developed in (Huang et al., 2010). This methodology of modular design of the product, from the normalization of constituent parts, it introduces a large degree of flexibility in the range of range of the final product. Although it will primarily economies of scale owing variety of end products and that also enables power in certain circumstances, economies of diversity (scope) (Dornier et al., 1998). With regard to the reporting of this "modularized design" is the practice of design, production and assembly of complete products from different modules from various sources, as occurs for example in modular computers, automobiles, and so on.

Finally, the most important tool from the decision support group is the "Analytical Hierarchy Process" (AHP). This is a methodology useful in screening and ranking the various decisions that must be made in companies engaged in the NPD, primarily with respect to the various alternatives under consideration. Due to the consideration of a large number of quantitative and qualitative criteria and lack of sufficient and concrete data, it is often the situation in which the members of the project group NPD have to make decisions in such situations of uncertainty. As with other tools or techniques, for example the DEA or, at the planning stage when the product specifications, the weighting (assigning weights) of factors and criteria is an essential exercise, and should be done in a way as reliable as possible (Chan et al., 2006). These criteria need to be considered and evaluated at the design and like the other methods, the solution may pass through the involvement of a group of experts multifunction (Fuzzy-Delphi). In obtaining the hierarchy adopted for making such decisions, the application of AHP tool, enables the distribution and selection of the most important among the various comparison and evaluation (Ayag and Ozdmir, 2009).

\subsection{Graph of the Most used Methodological Tools in NPD}

The survey on web of science mentioned in point 2 , leaded to make the matrix shown in figure 3 that relates the most important and used tools in NPD. Hence it was found the following:

1. From a first group arise that: the robust design; AHP and QFD are used very often in NPD (20.6 $\%$ of analyzed articles)

2. Of the six tools specified in respect of 22 analyzed $(23.5 \%)$ corresponded, on the whole, more than half of the articles surveyed (51.5\%);

3. The observations were less in the downward direction: the cause and effect diagram or (fishbone or Ishikawa) and DFMEA (about $1 \%$ of the total products);

4. The tools support the quality function of NPD lead with $27 \%$ of the articles;

5. The tools supporting innovation function accounted for $23.8 \%$ of the research articles, soon followed by tools supporting project (excluding the DFSS) with $16.6 \%$ of the tools and decision support with $15.8 \%$. The tools of DFSS projects for six sigma productions were scrutinized with $11.6 \%$ of the total;

6. AS tools focusing on the involvement of suppliers in collaborative processes stayed with $5.1 \%$. Despite being by far the least scientifically working group, differentiation which show the other face is so substantial that do not hesitate whether to maintain classification as special tool;

7. The tools support the quality function are those that interact more with the other while being the tool DFMEA (instrumental) used less and also less interacts ;

8. Of total tools, articles related to methodological tools was $65.5 \%$, while the corresponding articles of the type tools instrumental presented with the remaining $34.5 \%$;

9. The methodological tools used in most scientific papers were DFSS, TRIZ and the robust project 
with $45.7 \%$ for the set of methodological tools and $28.1 \%$ of the total;

10. The tools used were more instrumental HOQ, the DEA and the DOE with $70.2 \%$ of the total of such tools and $21.4 \%$ of the total sample

However, if it is adopted the term model as a simplified representation of the study object which contains not all elements, but only those considered relevant, graphs can be used to model interrelationships. Thus, the "nodes" are used to represent the tools while the "links" are used to represent the relationships between tools (Wasserman and Faust, 1994).

The cells of the matrix shown in figure 3 were used with ORA software, generating the graph shown in figure 1 . This figure illustrates the network of tools and their inter-relationships in NPD, where the nodes' size represents the number of times that a tool has been given reference in the literature during the period in analysis, and link's width represents the number of times that two tools are used simultaneously in NPD. AN

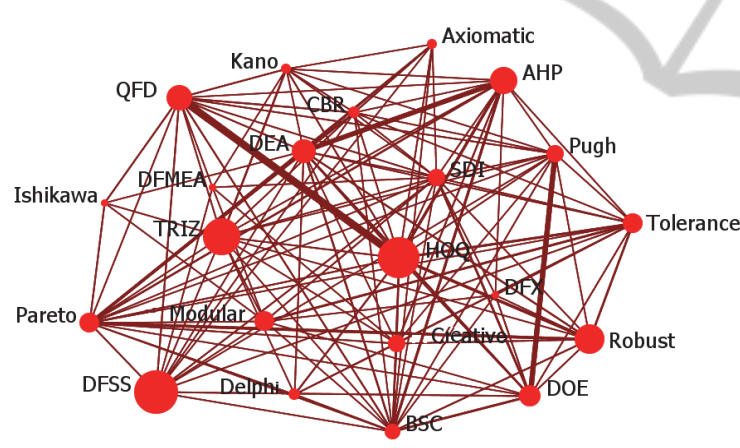

Figure 1: Importance of tools and their interrelationship in NPD.

In Figure 2, are represented the relations more relevant.

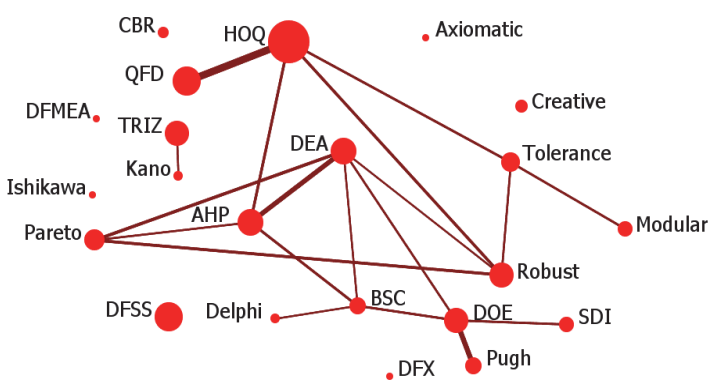

Figure 2: Simplified graph with the most relevant interrelationship in NPD.

One interesting advantage of using a graph approach is the possibility to analyze in detail the 'sub-structures' that may be present in the network. Divisions of tools into cliques, i.e. sub-structures of a network in which tools are more closely and intensely linked to one another than they are to other tools of the network, can be important to detect patterns of interrelationships between them.

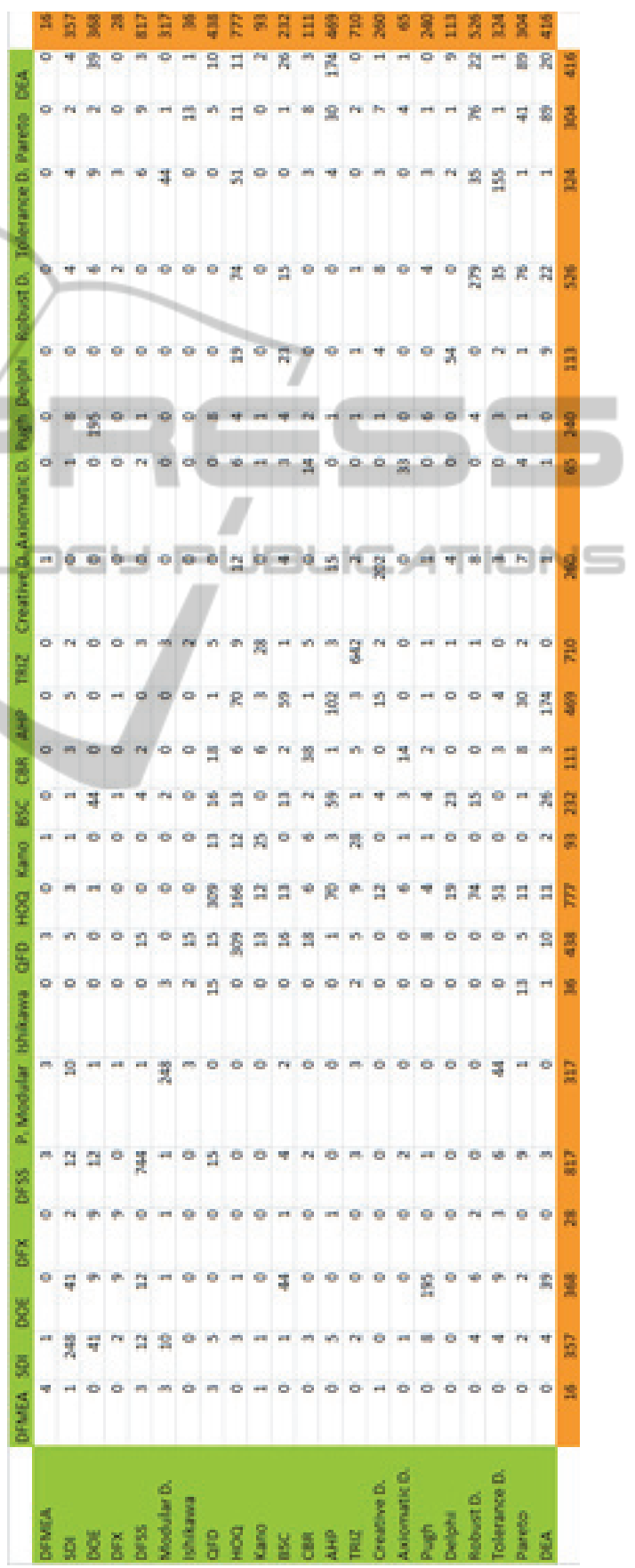

Figure 3: Matrix obtained from a survey conducted on web of science ( 594 articles were selected, gathering the period between 2002 and 2013). 
On the other hand, at micro level the knowledge how a tool is embedded in a sub-structure within a network, may be important to understand its applicability. For instance, some tools can act as 'bridges' between groups of tools.

Furthermore, applying metrics used in networks (graphs) for instance the concept of local centrality it is possible to identify that the most relevant tools used in NPD, alone or in complementary with others tools, are respectively, the HOQ DFSS and TRIZ ( $29.3 \%$ of total sample).

\section{CONCLUSIONS}

The literature review involves intrinsically NPD with a panoply of tools both methodological and structural root as a mostly instrumental. There were analyzed 22 of these tools, the most important has been possible with the survey of about seven thousand articles referenced in the web of science, interrelated and viewed graphically with the help of graphs appropriate. This selection addressed to the surface 10 to the Methodological tools, nevertheless accounted for $65.5 \%$ of the total sample collected.

The tools in use are classified into two types: methodological and vehicles. The first, by itself or as a complement to other, structure a project NPD (for example: TRIZ, DFSS or SDI). The latter alone can not structure a project or set of NPD, but which are recurrently used as support, support or other instrument (for example: Pareto analysis, balanced scorecard or BSC and Delphi panel).

\section{REFERENCES}

De Feo, J. and Bar-El, Z., 2002. Creating strategic change more efficiently with a new design for Six Sigma process, Journal of Change Management, Vol. 3, No. 1, pp.60-80.

Detanico, F. B., Teixeira, F. G. e Silva, T. K., 2010, A Biomimética como Método Criativo para o Projeto de Produto, Design \& Tecnologia, 02, pp. 101-113.

Finster, M., 2001. From continuous improvement to continuous innovation, Quality Management Journal, Vol. 8, No.4.

Christopher, M., 1992. Logistics and Supply Chain Management, Second Edition, Prentice Hall.

Creveling, C. M., Slutsky J. L., and Antis D. Jr., 2003. Design for Six Sigma - In Technology and Product Development, Prentice Hal PTR.

Wasserman, S. and Faust, K., 1994. Social Network Analysis - Methods and Applications, Cambridge University press.
Pin, C. S., Haron, F., Sarmady, S., Talib, A. Z. and Khader, A. T., 2011 Applying TRIZ principles in crowd management, Safety Science, 49, pp. 286-291.

Berdanosov, V. and Redkolis, E., 2011. TRIZ - Fractality of mathematics, Procedia Engineering, 9, pp. 461 472.

Ulrich, K. T. and Eppinger, S. D., 2002. Product, Design and Development, 2nd Edition, Irwin McGraw-Hill.

Gomes, P., Seco, N., Pereira, F. C., Paiva, P., Carreiro, P., Ferreira, J. L. and Bento, C., 2006. The importance of retrieval in creative design analogies, KnowledgeBased Systems, 19, pp. $480-488$.

Yang, K. and El-Haik, S. B., 2009. Design for Six SigmaA Roadmap for Product Development, Second Edition, McGraw-Hill.

Li, J. Y., Chen, X. B. and Zhang, W. J., 2011. AxiomaticDesign-Theory-Based Approach to Modeling Linear High Order System Dynamics, IEEE/ASME Transactions on Mechatronics, 16, (2), (2011), pp. 341-350.

Wynstra, F., Anderson, J. C., Narus, J. A. e Wouters, M., 2012. Supplier Development Responsibility and NPD Project Outcomes: The Roles of Monetary Quantification of Differences and Supporting-Detail Gathering, Journal of Production |Innovation Management, 29, pp. 103-123.

Jayaram, J., 2008. Supplier involvement in new product development projects: dimensionality and contingency effects, International Journal of Production Research, 46 (13), pp. 3717-3735.

Li, Y-L., Tang, J-F., Chin, K-S., Han, Y. and Luo, X-G., 2012. A rough set approach for estimating correlation measures in quality function deployment, Information Sciences, 189, pp. 126-142.

Mendonça, M. C. L. V. and Dias, J. C. Q., 2007. Postponement in The Logistical Systems of the New Automobiles Marketed in Portugal: The Brands And Quality, Total Quality Management \& Business Excellence, 18 (6), pp. 681-696.

Ghinato, P., 1998. Quality control methods: Towards modern approaches through well established principles, Total Quality Management, 9 (6), pp. 463 477.

Sun, H. and Zhao, Y., 2010. The empirical relationship between quality management and the speed of new product development, Total Quality Management, 21 (4), pp. 351-361.

Jou, Y. T., Chen, C. H., Hwang, C. H., Lin, W. T. and Huang, S. J., 2010. A study on the improvements of new product development procedure performance - an application of design for Six Sigma in a semiconductor equipment manufacturer, International Journal of Production Research, 48 (19), 1, pp. 2010, 5573-5591.

Shahin, A., 2008. Design for Six Sigma (DFSS): lessons learned from world-class companies, International Journal of Six Sigma and Competitive Advantage, 4 (1), pp. 48-59.

Lee, C. L. and Tang, G. R., 2000. Tolerance design for products with correlated characteristics, Mechanism 
and Machine Theory, 35, pp. 1675 - 1687.

Kang, N., Kim, J. and Park, Y., 2007. Integration of marketing domain and R\&D domain in NPD design process, Industrial Management \& Data Systems, 107 ( 5-6), pp. 780-801.

Santos, D., 2009. Beyond Six Sigma - A Control Chart for Tracking Defects per Billion Opportunities (dpbo), International Journal of industrial Engineering-theory Applications and Practice, 16, Special Issue: SI(3), pp. 227-233.

Singh, P., K., Jain, S. C. and Jain, P. K., 2005. Advanced optimal tolerance design of mechanical assemblies with interrelated dimension chains and process precision limits, Computers in Industry, 56, pp. 179194.

Zhang, J., e Li, S. P., Bao, N.S., Zhang, G. J. and Gu, P. H., 2010. A robust design approach to determination of tolerances of mechanical products, CIRP Annals Manufacturing Technology, 59, pp. 195-198.

Hagen, M. and Park, 2013. Ambiguity Acceptance as a Function of Project Management: A New Critical Success Factor, Project Management Journal, 44 (2), pp. 52-66.

Salvador, F. and Villena, V. H., 2013. Supplier integration and npd outcomes: conditional moderation effects of modular design competence, Journal of Supply Chain Management, 49 (1), pp. 87-113.

Huang, T-T., Le Chen, and Stewart, E. A., 2010. The moderating effect of knowledge sharing on the relationship between manufacturing activities and business performance, Knowledge Management Research \& Practice, 8, pp. 285-306.

Dornier, P. P., Ernest, R., Fender, M. and Kouvelis, P., 1998. Global Operations and Logistics -Text and Cases, John Wiley \& Sons, Inc.

Chan, F., Chan, H., Lau, H. and Ip, R., 2006 An AHP approach in benchmarking logistics performance of the postal industry, Benchmarking: An International Journal, 13 (6), pp.636-661.

Ayag, Z. and Ozdemir, R. G., 2009. A hybrid approach to concept selection through fuzzy analytic network process, Computers \& Industrial Engineering, 56, pp. $368-379$. 